\title{
INTERFERÊNCIA DE PLANTAS DANINHAS NA CULTURA DA CENOURA EM DOIS SISTEMAS DE IRRIGAÇÃO LOCALIZADA
}

\author{
INTERFERENCIA DE LAS PLANTAS DE DANIN EN LA CULTURA DE \\ ZANAHORIAS EM DOS SISTEMAS DE RIEGO UBICADOS
}

\section{INTERFERENCE OF WEED PLANTS IN THE CARROT CULTURE IN TWO LOCATED IRRIGATION SYSTEMS}

Antônio batista C. Bisneto ${ }^{1}$; Laís Tereza Rêgo Tereza. Reginaldo²; Maria Alice Formiga. Porto $^{3}$; Tatiane Severo Silva ${ }^{4}$; Daniel Valadão Silva ${ }^{5}$

DOI: https://doi.org/10.31692/978-65-991061-4-9.163-168

\section{INTRODUÇÃO}

A cenoura (Daucus carota L.) é uma hortaliça da família Apiaceae, considerada um dos vegetais de raiz mais valiosos economicamente. O consumo mundial de cenoura é de aproximadamente 4,29 $\mathrm{kg}$ por pessoa ao ano, sendo uma importante fonte de alimento e nutrição (FREITAS et al., 2009). No Brasil a cenoura é de grande relevância para o setor hortícola, ocupando a quinta posição entre as hortaliças com maior participação na produção do país (CARVALHO et al., 2017).

A irrigação da cenoura, como na maioria das olerícolas, além de ser um importante fator de produção, é o que mais favorece o aumento da produtividade. No entanto o déficit e ou excesso de água, podem propiciar condições desfavoráveis ao desenvolvimento da cenoura e levar a queda na produtividade dessa cultura (LIMA JÚNIOR, 2011). A região de Mossoró, Estado do Rio Grande do Norte, Brasil, é uma região que está dentro do semiárido Brasileiro, onde um dos fatores limitante para a produção agrícola é os limitados recursos hídricos naturais, que são altamente explorados. A agricultura irrigada é uma das principais atividades econômicas nessa região, e as olerícolas são cultivadas sob o método de irrigação localizada, com a utilização dos sistemas de irrigação por gotejamento e microaspersão, o que permite obtenção de colheitas nas épocas secas do ano.

Embora a irrigação contribua para melhoria do rendimento das culturas agrícolas, a interferência causada pelas plantas daninhas constitui um fator importante de limitação da produção na cultura da cenoura. A competição entre as daninhas e a cultura pode promover

\footnotetext{
${ }^{1}$ Agronomia, UFERSA, bisneto.ribeiro@gmail.com

${ }^{2}$ Graduada em Agronomia, UFERSA, laisttorquato@gmail.com

${ }^{3}$ Msc Fitotecnia, UFERSA, mariaalice6@hotmail.com

${ }^{4}$ Msc Fitotecnia, UFERSA, tatiane.severosilva@gmail.com

${ }^{5}$ Doutor, UFERSA, daniel.valadao@ufersa.edu.br
} 
significativas alterações na fisiologia da planta cultivada, podendo comprometer seu crescimento, produtividade e a qualidade do produto colhido (SARDANA et al., 2017).

Normalmente, os períodos de interferência das plantas daninhas são determinados por análises do decréscimo de características quantitativas e qualitativas. Em função da época de convivência e controle, é possível estimar o período anterior à interferência (PAI), o período total de prevenção à interferência (PTPI) e o período crítico de prevenção à interferência (PCPI), a partir dos quais é determinado o momento teoricamente mais adequado para o controle da comunidade de plantas daninhas (PITELLI, 1985 apud COELHO et al., 2017).

A cenoura apresenta baixa competitividade com plantas daninhas devido à sua lenta emergência e crescimento no início do ciclo de cultivo. Portanto, o objetivo desse estudo foi determinar os períodos de interferência de plantas daninhas em cenoura sob o sistema de irrigação por gotejamento e microaspersão.

\section{FUNDAMENTAÇÃO TEÓRICA}

As plantas daninhas representam um dos principais obstáculos para o sucesso da produção agrícola e são responsáveis por consideráveis perdas de rendimento nos sistemas de produção. A cenoura exerce fraca competição em relação às espécies de plantas daninhas, por apresentar características de crescimento inicial lento e porte baixo (NASCIMENTO et al., 2007). Os sistemas de produção de cenoura abrangem alta fertilização, preparo intensivo do solo e fornecimento constante de água. Este sistema favorece o estabelecimento de plantas daninhas, que, quando manuseado incorretamente, pode reduzir a produtividade e qualidade da raiz (TEÓFILO et al., 2009; SASNAUSKAS et al., 2012).

O método mais utilizado para o controle de plantas daninhas em lavouras de cenoura em larga escala tem sido a aplicação de herbicidas (KONIECZKA et al., 2009; SASNAUSKAS et al., 2012). No entanto, para um manejo de plantas daninhas mais sustentável economicamente e ambientalmente é necessário identificar o período crítico de interferência das plantas daninhas, visando conhecer o momento mais adequado para início e fim do controle das plantas daninhas durante o ciclo de cultivo.

A competição exercida pelas plantas daninhas constitui um dos fatores que mais limitam a produtividade da cultura da cenoura. A intensidade da competição normalmente é avaliada por meio de decréscimos de produção ou pela redução no crescimento da planta cultivada, como respostas à competição pelos recursos de crescimento disponíveis no ambiente (AGOSTINETO et al., 2008). Assim, é importante conhecer as limitações da cultura em relação a interferência causada pelas plantas daninhas que auxiliem na tomada de decisão 
para o controle.

\section{METODOLOGIA}

O experimento foi conduzido entre os meses de julho a novembro de 2018 na fazenda experimental Rafael Fernandes da Universidade Federal Rural do Semi-Árido, Mossoró-RN,

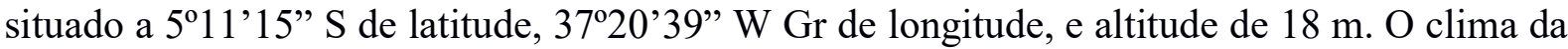
região, segundo a classificação de Köppen, é BSwh', seco e muito quente (CARMO FILHO et al., 1991). O preparo do solo foi realizado no sistema convencional, com aração, gradagem e formação dos canteiros com enxada rotativa. Para adubação de plantio foi realizada a análise química do solo. Considerando a recomendação do IPA (2008), aplicando $220 \mathrm{~kg} \mathrm{ha}^{-1}$ de $\mathrm{P}_{2} \mathrm{O}_{5}$ por ocasião do plantio.

A cenoura utilizada para desenvolvimento do experimento foi a cultivar "Suprema", semeada manualmente, depositando quatro sementes por cova de plantio, em seis linhas. O espaçamento utilizado foi de 0,15 m entre linhas e 0,08 m entre plantas. Aos 15 dias após a emergência (DAE) foi realizado o desbaste na cultura, deixando apenas uma planta por cova. Para adubação de cobertura foi aplicado $40 \mathrm{~kg} \mathrm{ha}^{-1}$ de nitrogênio, $60 \mathrm{~kg} \mathrm{ha}^{-1}$ de $\mathrm{P}_{2} \mathrm{O}_{5}$ e $30 \mathrm{~kg}$ $\mathrm{ha}^{-1}$ de $\mathrm{K}_{2} \mathrm{O}$, na forma de ureia, superfosfato simples e cloreto de potássio, respectivamente. A capina foi realizada por meio do arranquio manual, e não foram utilizados herbicidas.

O delineamento experimental utilizado foi o de blocos casualizados, com três repetições, no esquema de parcelas subdivididas. As parcelas foram constituídas dos dois sistemas de irrigação (gotejamento e microaspersão), e as subparcelas corresponderam à duração de convivência de plantas daninhas nos tratamentos, sendo divididos em dois grupos, constituídos de períodos de controle (no limpo) ou convivência (no mato) das plantas daninhas com a cultura.

Os tratamentos foram implementados desde o início da emergência da cenoura: (i) as parcelas foram deixadas com plantas daninhas durante 10, 20, 30, 40, 50, e 120 dias após emergência (DAE) para avaliar o início do período crítico de remoção das plantas daninhas e (ii) as parcelas foram mantidas sem plantas daninhas por 10, 20, 30, 40, 50, e 120 DAE para determinar o fim do período crítico.

A frequência e matéria seca de plantas daninhas foram avaliadas descritivamente entre os tratamentos ao longo dos 120 dias de cultivo da cenoura. Para definir os períodos de interferências nos diferentes tratamentos, foi utilizado o Modelo Sigmoidal 4 parâmetros. Os valores do período anterior a interferência (PAI), período crítico de prevenção a interferência (PCPI) e período total de prevenção a interferência (PTPI) foram comparados 
descritivamente.

\section{RESULTADOS E DISCUSSÃO}

A produtividade relativa da cenoura foi afetada em ambos os sistemas de irrigação utilizados, porém observa-se que no sistema de irrigação por microaspersão o período de início e do final do PCPI foi reduzido em comparação ao sistema de gotejamento que apresentou maior período de interferência (Figura 1).

Figura 1. Produtividade relativa da cenoura (\%), sem e com competição com plantas daninhas, em sistema de gotejo (a) e microaspersão (b) durante 120 dias após a emergência.
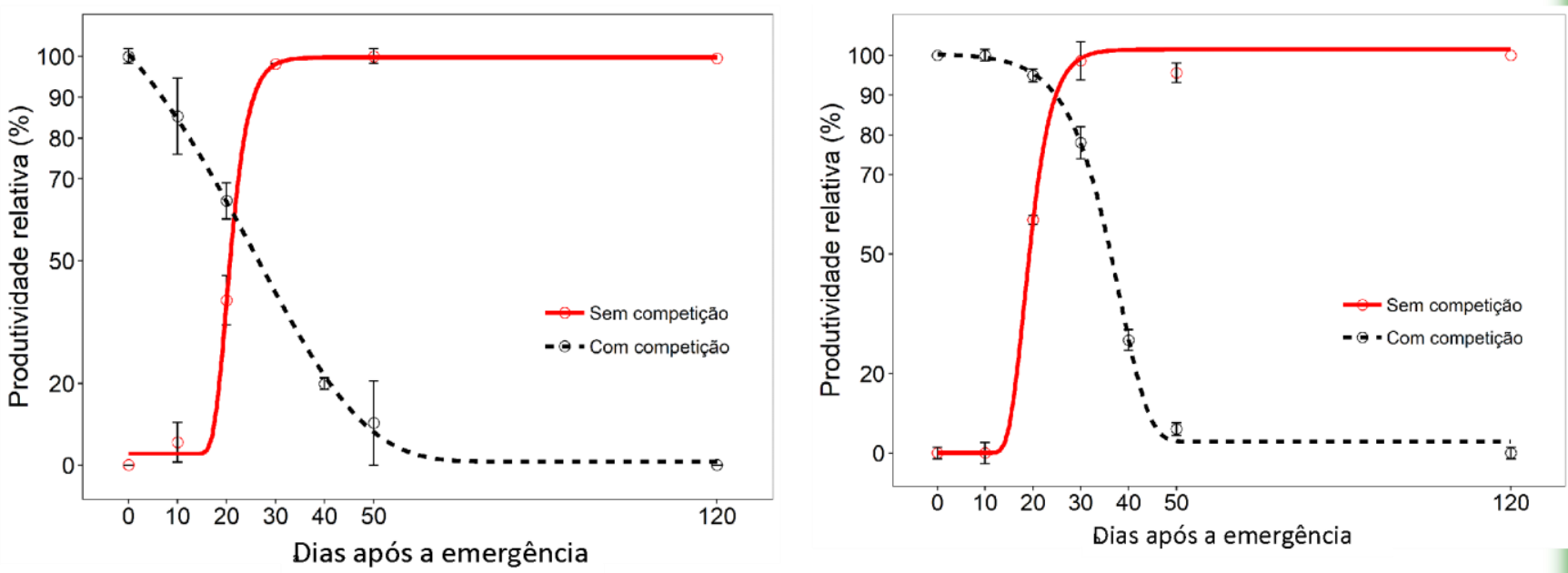

O rendimento das raízes de cenoura foi reduzido por atrasos prolongados na remoção de plantas daninhas nos dois sistemas de irrigação. Por outro lado, o rendimento das raízes de cenoura aumentou com a crescente duração do período livre de plantas daninhas nos dois sistemas de irrigação (Figura 1).

Os períodos de interferência das plantas daninhas variaram entre os sistemas de irrigação (Figura 1). Considerando uma perda aceitável de $5 \%$ para o sistema de gotejamento o PAI estabelecido foi de 4 DAE, e o PCPI de 23 dias, obtendo um PTPI de 27 DAE (Tabela 1). No sistema de microaspersão considerando a perda aceitável de $5 \%$, o PAI estabelecido para a cultura foi de 20 DAE, com PCPI de 7 dias e PTPI de 27 DAE (Tabela 5).

Tabela 1. Período anterior a interferência (PAI), período crítico de prevenção a interferência (PCPI) e período total de prevenção a interferência (PTPI) para o controle de plantas daninhas em dois sistemas de irrigação (gotejo e microaspersão) na cultura da cenoura, considerando uma perda aceitável de 5,0\%.

\begin{tabular}{lllll}
\hline \multirow{2}{*}{ Perda aceitável $(\%)$} & \multirow{2}{*}{ Sistema } & \multicolumn{3}{l}{ Períodos de interferência } \\
& & PAI & PCPI & PTPI \\
\cline { 2 - 5 } 5 & Gotejo & 4 & 23 & 27 \\
\cline { 2 - 5 } & Microaspersão & 20 & 7 & 27 \\
\hline
\end{tabular}

No presente estudo o PCPI variou nos dois cultivos da cenoura devido aos sistemas de [166] 
irrigação utilizados. No sistema de irrigação por gotejamento a capina das plantas daninhas deve ser iniciada mais cedo e o período em que a cultura deve ser mantida livre das plantas daninhas (PCPI) é maior, quando comparado ao sistema de irrigação por microaspersão.

A alta infestação de Digitaria. horizontalis Willd. no início de desenvolvimento da cultura pode ter sido o que mais influenciou para o controle de plantas daninhas mais cedo durante o ciclo de cultivo da cenoura no sistema de irrigação por gotejamento. Essa espécie daninha por ser uma planta de metabolismo $\mathrm{C}_{4}$ é melhor adaptada à temperatura e luz mais intensas, apresentando maior eficiência no uso da água (TAYLOR et al., 2011). Com isso, a menor disponibilidade de água nesse sistema pode ter intensificado a competição por esse recurso, limitando o crescimento e desenvolvimento da cultura. No sistema de irrigação por microaspersão devido a maior disponibilidade e distribuição da água, a competição por esse recurso pode ter sido menor e, portanto, a necessidade de iniciar o controle de plantas daninhas foi um pouco mais tardio.

\section{CONCLUSÕES}

O sistema de irrigação influencia o início e o fim do PCPI. O comprimento do PCPI no sistema de irrigação por gotejamento foi de 3,3 semanas (23 dias) e 1,0 semana (7 dias) considerando perdas de rendimento de 5,0 \%. No sistema de irrigação por gotejamento a capina das plantas daninhas deve ser iniciada mais cedo e o período em que a cultura deve ser mantida livre das plantas daninhas é maior, comparado ao sistema de irrigação por microaspersão. Os dados obtidos nesse estudo fornecem uma base inicial para os produtores de cenoura tomarem uma decisão em relação às medidas de controle oportunas de plantas daninhas.

\section{REFERÊNCIAS}

CARVALHO, A. D.F; SILVA, G. O. Divergência genética entre genótipos de cenoura através de caracteres agronômicos. Revista Agro@mbiente On-line, v. 11, n. 2, p. 137-144, abriljunho, 2017.

LIMA JUNIOR, J. A.; PEREIRA, G. M.; GEISENHOFF, L. O.; SILVA, W. G.; VILAS BOAS, R. C.; SOUZA, R. J. Desempenho de cultivares de cenoura em função da água no solo. Revista Brasileira de Engenharia Agrícola e Ambiental, Campina Grande, v. 16, n. 5, p. 514-520, 2012.

SARDANA, V. et al. Role of competition in managing weeds: An introduction to the special issue. Crop Protection, v. 95, p. 1-7, 2017.

PITELLI, R.A. A interferência de plantas daninhas em culturas agrícolas. Informativo 
Agropecuário, v.11, p.16-17, 1985.

DOSSA, D; FUCHS, F. CENOURA: Produção, mercado e preços na CEASA-PR. Boletim Técnico 04. CENOURA: Setembro de 2017.

VIEIRA, J. V et al. Cenoura (Daucus carota). Embrapa hortaliças. Sistema de Produção ,5, 2008.

EMBRAPA. Manual de Segurança e Qualidade para a Cultura da Cenoura. Brasília: EMBRAPA/SEDE, 61 p. 2004.

CARMO FILHO, F.; ESPÍNOLA SOBRINHO, J.; MAIA NETO, J. M. Dados climatológicos de Mossoró: um município semi-árido nordestino. Mossoró: UFERSA, 1991. (Coleção Mossoroense, C.30).

SILVA, ANA CAROLINA BIZINOTO; SCHUQUEL, LUENDA CAMILE DOS SANTOS,; SILVA, CASSIANO OLIVEIRA,; PASCOAL, GRAZIELI BENEDETI. Qualidade Nutricional e Físico-química em Cenoura (Daucus carota l.) In Natura e Minimamente Processada. Demetra; 2016; 11(2); 355-367 